\title{
Induction of Nevi and Skin Tumors in Ink4a/Arf Xpa Knockout Mice by Neonatal, Intermittent, or Chronic UVB Exposures
}

\section{Arne van Schanke ${ }^{1,2}$, Gemma M.C.A.L. van Venrooij ${ }^{2}$, Marjan J. Jongsma², H. Alexander Banus ${ }^{4}$, Leon H.F. Mullenders ${ }^{3}$, Henk J. van Kranen ${ }^{5}$ and Frank R. de Gruij| ${ }^{2}$}

${ }^{1}$ Dermatology Department, University Medical Centre Utrecht, Utrecht, the Netherlands; Departments of ${ }^{2}$ Dermatology and ${ }^{3}$ Toxicogenetics, Leiden University Medical Centre, Leiden, the Netherlands; ${ }^{4}$ Laboratory of VaccinePreventable Diseases; and ${ }^{5}$ Toxicology, Pathology, and Genetics Department, National Institute of Public Health and the Environment, Bilthoven, the Netherlands

Requests for reprints: Frank de Gruijl, Dermatology Department, Leiden University Medical Centre, PO Box 9600, 2300RC Leiden, the Netherlands. Phone: 31-71-5262497; E-mail: f.r.de_gruijl@lumc.nl

\begin{abstract}
Nevi and melanomas correlate to childhood and intermittent solar UV exposure, xeroderma pigmentosum patients run increased risk, and $\mathrm{p} 16^{\text {Ink } 4 a}$ expression is often lost in malignant progression. To ascertain the effect of these risk factors, pigmented hairless Ink4a/Arf-, Xpa- knockout mice were subjected to various combinations of neonatal [7,12-dimethylbenz(a)anthracene (DMBA) or UVB exposure] and adult treatments (12-O-tetradecanoylphorbol-13-acetate or subacute daily UVB exposure or intermittent overexposure). Nevi occurred earliest, grew largest, and were most numerous in mice exposed to DMBA followed by intermittent UVB overexposure [effect of six minimal edemal doses (MED), $1 x / 2$ weeks > 4 MED $1 x / w k]$. Neonatal UV exposure enhanced nevus induction but lost its effect after 200 days. The $\mathrm{Xpa}^{-/-}$mice proved exquisitely sensitive to UV-driven nevus induction, indicating the involvement of pyrimidine dimer DNA lesions, but $\mathrm{Xpa}^{+/+}$mice developed many more nevi ( $>40$ per mouse) at high UV dosages not tolerated by $\mathrm{Xpa}^{-/-}$mice. Ink4a/Arf ${ }^{-/-}$mice developed most skin tumors faster, but surprisingly developed nevi slower than their heterozygous counterparts especially after neonatal UV exposure. Despite raising $>1,600$ nevi, only six melanomas arose in our experiments with Ink4a/Arf knockout mice (five of which in $\mathrm{Xpa}^{+/+}$mice at high UV dosages). In contrast to human nevi, these nevi lacked hotspot mutations in Braf or Ras genes, possibly explaining the lack of malignant progression in the Ink $\mathrm{a} a / \mathrm{Arf}^{-1-}$ mice. Hence, although our experiments did not effectively emulate human melanoma, they provided clear evidence that intermittent UV overexposure strongly stimulates and the Ink4a/Arf ${ }^{-1}$ genotype may actually impair nevus development. (Cancer Res 2006; 66(5): 2608-15)
\end{abstract}




\section{Introduction}

The most important environmental risk factor for skin cancers, including cutaneous malignant melanomas, is exposure to solar UV radiation. Epidemiologic studies indicate that unlike squamous cell carcinomas (SCC), cutaneous malignant melanomas are not associated with chronic exposure, but with sunburns, especially those in childhood (1). Another important risk factor for cutaneous malignant melanoma is inheritance of mutations in so-called melanoma genes, which predispose individuals to the development of melanoma. Thus far, familial clusters have led to the identification of two melanoma genes: CDKN2A and CDK4 (2). The CDKN2A gene encodes two proteins-p16 Ink4a and $\mathrm{p} 14^{\text {Arf }} \cdot \mathrm{p} 16^{\text {Ink4a }}$ regulates cell cycle progression by inhibiting cyclin-dependent kinases, such as CDK4. Two exons in CDKN2A can form an alternative reading frame for the $14^{A r f}$ protein ( $19^{\text {Arf }}$ in mice; ref. 3 ), which enhances $\mathrm{p} 53$ function by blocking MDM2 (4). Mutations in the CDKN2A tumor suppressor gene impair the function of p16 $6^{\text {Ink4a }}$ and/or p14 ${ }^{\text {Arf }}$, thus facilitating "unauthorized" proliferation of cells with, for example, erroneous activation of the Ras pathway. This is illustrated by a highly increased $N$-Ras mutation frequency in melanomas of patients with germ line CDKN2A mutations (5). Uncontrolled proliferation may cause further mutation fixation in cells with (UV-) damaged DNA. Consequently, mice lacking both Ink4a and Arf have an enhanced sensitivity to tumorigenesis (6). Mice nullizygous for either $p 16^{\text {Ink4a }}$ or $p 19^{\text {Arf }}$ crossbred with Ras transgenes rapidly develop melanomas that lack expression of $\mathrm{p} 19^{\text {Arf }}$ or $\mathrm{p} 16^{\text {Ink4a }}$, respectively, indicating that both products of the $C D K N 2 A$ locus participate in melanoma suppression (7). Similarly, although CDKN2A is only completely lost or mutated in a minority of cutaneous malignant melanoma, most cutaneous malignant melanomas and their metastases lack p16 ${ }^{\text {Ink4a }}$ expression (8). The expression is usually high in nevi (9), which commonly bear activating mutations in the oncogenes Braf or $N$-Ras (9). Loss of $116^{\text {Ink4a }}$ cell cycle control thus seems to give way to the mitogenic signaling from Ras or Braf and contributes to progression of nevus to cutaneous malignant melanoma (10).

Sunlight causes various types of DNA damage, such as pyrimidine dimers, of which the importance in skin tumorigenesis is exemplified by characteristic signature mutations found in oncogenes and tumor suppressor genes in nonmelanoma skin cancer $(11,12)$.

Pyrimidine dimers can be repaired accurately by nucleotide excision repair. People with the rare genetic disorder xeroderma pigmentosum lack nucleotide excision repair and are up to 1,000 times more prone to skin cancers, including melanoma, compared with the general population (13). This condition can result from mutations in components of the nucleotide excision repair system, such as Xpa.

In wild-type mice, treatment with only UV radiation does not induce melanomas, but UV can accelerate their formation in combined treatments with chemical carcinogens (14-16). Similarly, UV radiation can strongly enhance melanoma formation in transgenic mouse strains that spontaneously develop these tumors (17).

Mice with a targeted deletion of the Ink4a/Arf locus do not develop melanomas spontaneously nor when exposed to UV radiation or chemical carcinogens (6). However, crossbreeding these mice with $H-R_{a s}{ }^{G 12 V}$ transgenic mice (carrying an activated Ras oncogene under a tyrosine promotor) raised the percentage of animals with melanomas from $2 \%$ in Ink $4 a$ /Arf wild types to $60 \%$ in Ink4a/Arf knockouts, illustrating the importance of CDKN2A in preventing melanoma (18). 
$H$-Ras mutations in keratinocytes can be effectively induced in Xpa knockout mice by chronic UV irradiation, leading to the formation of papillomas; however, no melanomas were observed in these experiments (19). We hypothesized that if $\mathrm{H}$ Ras (or $\mathrm{N}$-Ras) mutations could also be induced in melanocytes by UVB irradiation of Xpa knockout mice, and in crossbreds with Ink4a knockout mice, these Ras mutations could lead to the development of melanomas. Moreover, loss of $\mathrm{p} 16^{\text {Ink4a }}$ was found to be related to malignant progression of (UV-induced) skin carcinomas (20). The specific UV regimen (chronic versus intermittent exposure) can be expected to be decisive for the efficacy of different types of skin cancers. Therefore, we ascertained the skin tumorigenic effect of various UV exposure regimens on pigmented hairless Ink4a/Arf knockout and Ink4a/Arf Xpa doubleknockout mice, specifically looking at nevi induction (risk factor of melanomas and putative precursors) and progression to melanoma.

\section{Materials and Methods}

Mice. Ink4a/Arf knockout (courtesy of Drs. R. DePinho and L. Chin; ref. 6) and Xpa knockout mice (courtesy of Dr. Van Steeg; ref. 21 ) were crossbred $\left(F_{3}\right)$ in a pigmented hairless background ( $\mathrm{Hr}$, Charles River, Wilmington, $\mathrm{MA})$. Cohorts of neonates from three to five nests of Ink4a/Arf ${ }^{/-} \times$Ink $\mathrm{aa} / \mathrm{Arf}^{+/-}$parents entered the experiments, thus reproducing these genotypes in approximately equal numbers; in experiment 1 , all mice were $\mathrm{Xpa}^{-/-}$; in experiment 2 , all mice were $X \mathrm{pa}^{+/+}$.

Mice were kept as described (22) and permission was obtained from the Ethical Commission on Animal Experiments of the University Medical Center Utrecht, Utrecht, the Netherlands.

Chemical exposures. 7,12-Dimethylbenz(a)anthracene (DMBA) and 12-Otetradecanoylphorbol-13-acetate (TPA) were purchased from Sigma (Zwijndrecht, the Netherlands). Mice of the relevant cohorts were topically treated once at 3 days of age with $50 \mu \mathrm{L}$ DMBA solution $\left(0.2\right.$ or $2 \mathrm{mg} / \mathrm{mL}$ in acetone for $X p a^{-/-}$and $\mathrm{Xpa}^{+/+}$, respectively). Mice in the TPA-treated cohort were topically exposed twice a week to $50 \mu \mathrm{L}$ TPA solution $(0.5 \mathrm{mg} / \mathrm{mL}$ in acetone) commencing at 4 weeks of age until sacrifice.

UVB exposure. For UVB exposure, cages were placed in an automatically timeswitched irradiation setup (23) equipped with Philips TL12/40W lamps (Philips, Eindhoven, the Netherlands). The doses were expressed as multiples of the minimal edemal dose (MED, determined earlier; ref. 24). For TL12/40W lamps, 1 MED equals $500 \mathrm{~J} / \mathrm{m}^{2} \mathrm{UV}$ in $X p a^{+/+}$mice and $62.5 \mathrm{~J} / \mathrm{m}^{2}$ in $X p a^{-/-}$mice. Six MED was the highest tested dose that caused a clear sunburn without blistering or further complications that acutely compromised the condition of the animals (i.e., highest tolerated dose). For neonatal exposures, pups were exposed separately (to prevent shielding) under maximal lamp intensity for $\sim 15$ minutes, immediately after which pups and mothers were rejoined.

Experiment 1. This experiment aimed at optimizing a UVB irradiation scheme to induce melanocytic hyperplasia to form nevi based on a two-stage initiation/promotion protocol (16). First, five promotion treatments of adult mice were compared after neonatal application of DMBA. Subsequently, initiation with DMBA was compared with UV irradiation (4 MED at days 3, 4, and 5 of age) or sham treatment.

The regimens in the adulthood were as follows: I, daily exposure to a suberythemal dose of UVB (4/7 MED); II, an equal dose in a single weekly 
Cancer Research 66, 2608-2615, March 1, 2006

exposure (4 MED); III, exposure to the highest tolerated UVB dose (6 MED) once every fortnight; IV, TPA twice a week (positive control); V, sham. Neonatal treatments were compared using adult treatments I, III, and V. Two cohorts included Ink4a/Arf wild types (Table 1). 
Table 1. Overview of tumor outcomes for all treatments in this study

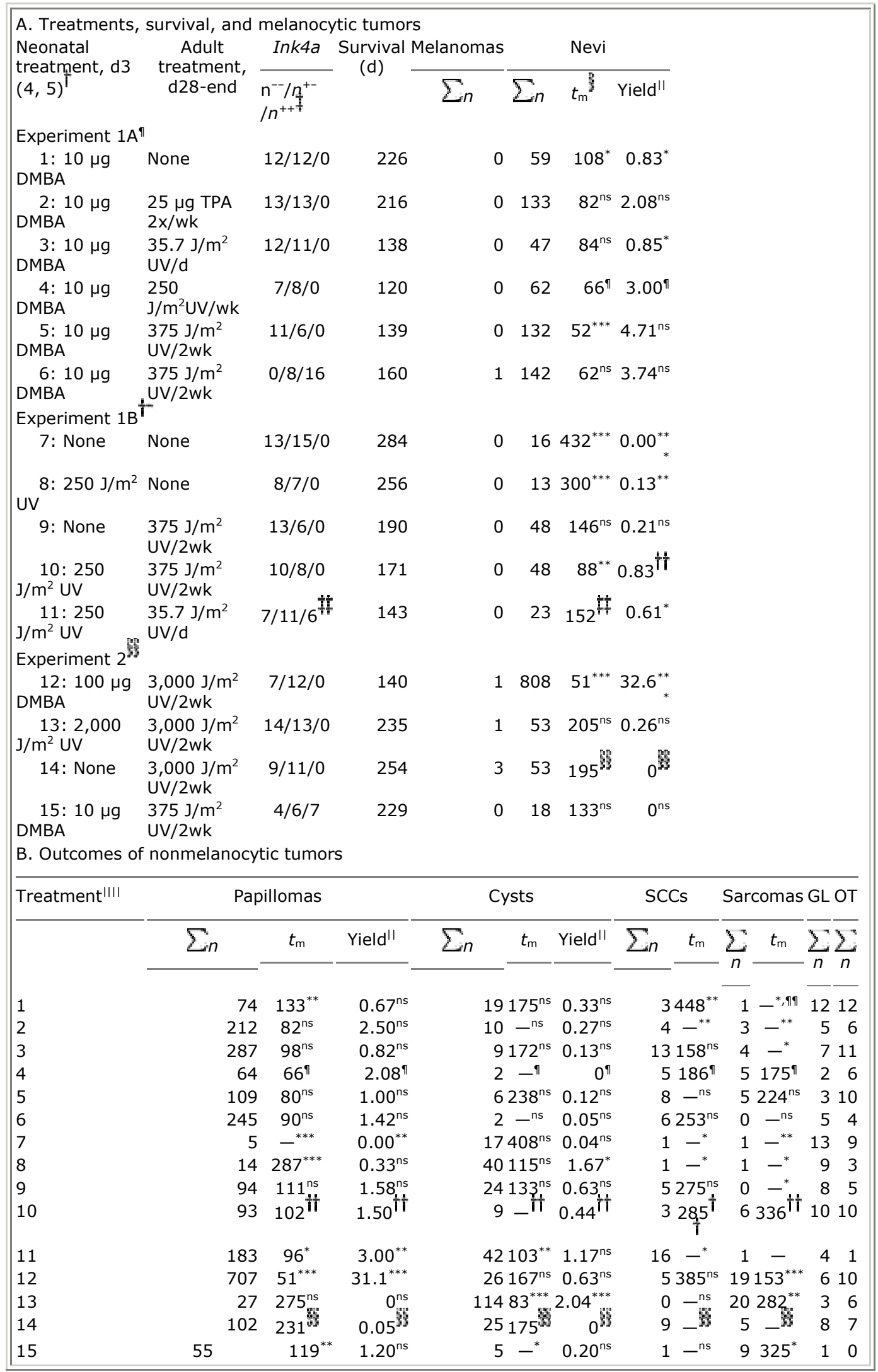


NOTE: Levels of significance for yields were obtained by ANOVA and for tumorfree survival by Cox regression (corrected for genotype effects).

Abbreviations: GL, generalized lymphoma; OT, other tumors such as heamangiomas, papillomas of the conjunctiva, lung, brain, and colorectal tumors; $\sum n$, total number of tumors observed per group; ns, not significant.

* DMBA treatment at day 3; UVB treatment at days 3, 4, and 5.

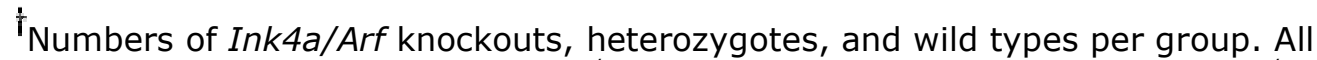
animals in experiment 1 were $\mathrm{Xpa}^{-/-}$; all animals in experiment 2 were $\mathrm{Xpa}^{+/+}$.

${ }^{\ddagger} t_{\mathrm{m}}$ values were obtained from Kaplan-Meier plots.

${ }_{Y i e l d s}$ were compared at 98 days (experiment $1 \mathrm{~A}$ ) or 140 days (experiments 1B and 2).

II For statistics, the group exposed weekly to $250 \mathrm{~J} / \mathrm{m}^{2}$ UV was used as reference group.

" Level of significance of $<0.05$.

** Level of significance of $<0.001$.

$\AA^{\dagger}$ For statistics, the group exposed neonatally to $250 \mathrm{~J} / \mathrm{m}^{2}$ and in adulthood to 375 $\mathrm{J} / \mathrm{m}^{2}$ UV per fortnight was used as reference group.

\#Level of significance of $<0.01$.

${ }^{2}$ For uniformity, statistical comparisons are based on homozygous knockouts and heterozygotes only.

IIII For statistics, the group sham exposed neonatally and to $3,000 \mathrm{~J} / \mathrm{m}^{2} \mathrm{UV}$ per fortnight in adulthood was used as reference group.

กๆ Numbers refer to Table $1 \mathrm{~A}$.

*** Could not be calculated (percentage of affected animals never reached 50 ).

Experiment 2. Ink4a/Arf ${ }^{-/}$mice $\left(\mathrm{Xpa}^{+/+}\right)$were neonatally exposed to DMBA, UV, or sham treated, followed by adult promotion treatment III. Doses were adapted (see above) to Xpa wild-type mice, which are less sensitive than $X p a^{-/-}$mice to the acute effects of UVB radiation and DMBA. To allow a complete comparison, we included a cohort of Ink4a/Arf knockout mice $\left(\mathrm{Xpa}^{+/+}\right)$receiving exactly the same low doses (expressed in $\mathrm{J} / \mathrm{m}^{2} \mathrm{UV}$ or $\mu \mathrm{g}$ DMBA) as the Ink4a/Arf knockouts in an $\mathrm{Xpa}^{-/-}$background. The treatments for both experiments are summarized in Table 1.

Characterization of tumors. Mice were checked weekly to record tumors and other abnormalities (23), and kept until tumors $>10 \mathrm{~mm}$ across developed, illness occurred, or until 16 months of age. After sacrifice, the organs were thoroughly screened for abnormalities and samples of nevi and (skin) tumors were collected in formalin. Paraffin-embedded $5 \mu \mathrm{m}$ tissue sections were H\&E stained and 
evaluated by experienced pathologists. To establish the diagnosis, immunohistochemical stainings were done with the following antibodies:

polyclonal goat anti-mouse Trp-1 (1:100, Santa Cruz Biotechnology, Heidelberg, Germany), polyclonal goat anti-human Trp-2 (1:100, Santa Cruz Biotechnology), monoclonal mouse anti-human Melan-A/Mart-1 (1:500, clone A103, DAKO, Glostrup, Denmark), polyclonal rabbit anti-cow S100 (1:8,000, DAKO), monoclonal mouse anti-B-smooth muscle actin (1:10,000, clone 1A4, Sigma), and monoclonal mouse anticytokeratin (1:100, clone AE1/AE3, Chemicon, Temecula, CA).

Proliferative signaling in nevi was established by staining with polyclonal rabbit anti-human Ki-67 (1:1,000, Novocastra, Newcastle upon Tyne, United Kingdom), polyclonal rabbit anti-human pERK1/2 (1:200, Cell Signaling, Beverly, MA), and rabbit polyclonal anti-p53 (1:500, CM-5, Novocastra). Sections from murine SCCs and colon cancers served as positive controls for proliferation markers.

Microdissection and mutation analyses. From mice of each treatment group, nevi over $2 \mathrm{~mm}$ in diameter $(n=46)$ and all melanomas $(n=6)$ were analyzed for mutations. Five-micrometer sections of nevi and melanomas were fixed on PEN foil-coated glass slides (Leica Microsystems, Wetzlar, Germany) and deparafinized. Specimens (unstained) of at least 50 cells were microdissected using an AS LMD laser microdissection microscope (Leica Microsystems) and collected in $8 \mathrm{~mL}$ FLB buffer with Proteinase-K (NucleoSpin DNA Trace kit, Machery Nagel, Düren, Germany). DNA was isolated using NucleoSpin columns according to the instructions of the manufacturer.

Fragments of Braf exon 15, $\mathrm{N}$-Ras exons 1 and 2, $\mathrm{H}$-Ras exons 1 and 2 , and $\mathrm{K}$ Ras exons 1 and 2 were PCR amplified in single fashion (primers and fragment sizes; Table 2). PCR reactions contained $25 \mu \mathrm{L}$ Hotstar Taq Master Mix (Qiagen, Venlo, the Netherlands), 60 pmol of each primer, and $5 \mu \mathrm{L}$ DNA ( $* 5 \mathrm{ng})$ per reaction (total volume $25 \mu \mathrm{L}$ ). PCR products were reamplified in a $25 \mu \mathrm{L}$ reaction. Depending on sequencing direction (Table 2), the $3^{\prime}$ or 5 ' end of the PCR product was biotinylated using biotinylated primers. 
Table 2. PCR and pyrosequencing primers and mutations observed in nevi $(n=46)$ and melanomas $(n=6)$

\begin{tabular}{|c|c|c|c|c|c|}
\hline Gene & PCR primers: universal biotinylated, gene-specific forward and reverse & $\begin{array}{l}\text { Amplicon } \\
\text { size }\end{array}$ & $\begin{array}{l}\text { Pyrosequencing primer } \\
\text { (sequencing direction) }\end{array}$ & $\begin{array}{l}\text { Informative } \\
\text { sequences (\%) }\end{array}$ & $\begin{array}{l}\text { Mutations } \\
\text { found }\end{array}$ \\
\hline $\begin{array}{l}\text { Braf } \\
\text { exon } 15\end{array}$ & $\begin{array}{l}\text { Uni-biotin-rev }{ }^{*}, \text { 5'-TTCCTTACTTACTGCACCTCAGA-3'; 5'- } \\
5 \text { AGCGCTGCTCCGGTTCATAGATTCCATCCACAAAATAGATCCAGA-3' }\end{array}$ & 127 & $\begin{array}{l}\text { GTGACTTTGGTCTAGCCAC } \\
\text { (forward) }\end{array}$ & 60 & None \\
\hline $\begin{array}{l}N \text {-Ras } \\
\text { exon } 1\end{array}$ & $\begin{array}{l}\text { Uni-biotin-rev, 5'-ACAGGTTTTTGCTGGTGTGA-3'; 5'- } \\
\text { AGCGCTGCTCCCGGTTCATAGATTCATCCACAAAGTGGTTCTGG-3' }\end{array}$ & 112 & $\begin{array}{l}\text { AAACTGGTGGTGGTTGGAGC } \\
\text { (forward) }\end{array}$ & 82 & None \\
\hline $\begin{array}{l}N \text {-Ras } \\
\text { exon } 2\end{array}$ & $\begin{array}{l}\text { Uni-biotin-for }{ }^{\dagger}, 5^{\prime} \text {-GGGACACCGCTGATCGTTTATCCCAGGATTCTTACCGAAA-3'; 5'- } \\
\text { CCTTCGCCTGTCCTCATGTA-3' }\end{array}$ & 125 & $\begin{array}{l}\text { AGGAGTACAGTGCCATGAGA } \\
\text { (reverse) }\end{array}$ & \multicolumn{2}{|c|}{$\begin{array}{c}70 \mathrm{C}>\mathrm{T}, \text { codon } 60 \\
(1 \text { nevus })\end{array}$} \\
\hline $\begin{array}{l}H \text {-Ras } \\
\text { exon } 1\end{array}$ & $\begin{array}{l}\text { Uni-biotin-rev, 5'-CTGGCTAAGTGTGCTTCT-3'; 5'- } \\
\text { AGCGCTGCTCCGGTTCATAGATTGGTGAGCTCTGCCTACCTGC-3' }\end{array}$ & 199 & AGCTTGTGGTGGTG (forward) & 41 & None \\
\hline $\begin{array}{l}H \text {-Ras } \\
\text { exon } 2\end{array}$ & $\begin{array}{l}\text { (No universal biotinylated primer) 5'-CGTGTTGTTTTGCAGGACTC-3'; 5'-biotin- } \\
\text { labeled-ATGTACTGGTCCCGCATGG-3' }\end{array}$ & 122 & $\begin{array}{l}\text { GGACATCTTAGACACAGCAG } \\
\text { (forward) }\end{array}$ & 73 & None \\
\hline $\begin{array}{l}K \text { K-Ras } \\
\text { exon } 1\end{array}$ & $\begin{array}{l}\text { Uni-biotin-rev, 5'-AGGCCTGCTGAAAATGACTG-3'; 5'- } \\
\text { AGCGCTGCTCCGGTTCATAGATTCGTAGGGTCATACTCATCCAC-3' }\end{array}$ & 118 & $\begin{array}{l}\text { AAACTTGTGGTGGTTGGAGC } \\
\text { (forward) }\end{array}$ & \multicolumn{2}{|c|}{$\begin{array}{c}89 \mathrm{G}>\mathrm{A}, \text { codon } 13 \\
\text { (1 nevus) }\end{array}$} \\
\hline $\begin{array}{l}\text { K-Ras } \\
\text { exon } 2\end{array}$ & $\begin{array}{l}\text { Uni-biotin-rev, 5'-TTGGATATTCTCGACACAGCA-3'; 5'- } \\
\text { AGCGCTGCTCCGGTTCATAGATTTAAACCCACCTATAATGGTGAA-3' }\end{array}$ & 144 & $\begin{array}{l}\text { GATATTCTCGACACAGCAGG } \\
\text { (forward) }\end{array}$ & 87 & None \\
\hline
\end{tabular}

* 5'-Biotin-GGGACACCGCTGATCGTTTA-3' (universal biotinylated forward primer).

'†'-Biotin-GCTGCTCCGGTTCATAGATT-3' (universal biotinylated reverse primer). 
Biotinylated PCR products were immobilized on streptavidin Sepharose HP beads (B\&L Systems, Maarssen, the Netherlands) in binding buffer $[10 \mathrm{mmol} / \mathrm{L}$ Tris- $\mathrm{HCl}$, $2 \mathrm{~mol} / \mathrm{L} \mathrm{NaCl}, 1 \mathrm{mmol} / \mathrm{L} \mathrm{EDTA}$, and $0.1 \%$ Tween 20 (pH 7.6)]. The beads were transferred to a $0.2 \mathrm{~mol} / \mathrm{L} \mathrm{NaOH}$ solution to separate the strands. The beads containing the biotinylated strand were washed in $10 \mathrm{mmol} / \mathrm{L}$ Tris-acetate $(\mathrm{pH}$ 7.6) and fed into a 96-well plate containing the pyrosequencing primer $(0.15 \mu \mathrm{L}$, $100 \mathrm{pmol} / \mu \mathrm{L})$ and annealing buffer $[44.85 \mu \mathrm{L}, 20 \mathrm{mmol} / \mathrm{L}$ Tris-acetate, and 2 $\mathrm{mmol} / \mathrm{L} \mathrm{MgAc} 2$ (pH 7.6)].

The plate was transferred into a PSQ96MA (Pyrosequencing, Biotage, Uppsala, Sweden) where real-time sequencing was done of the sequences surrounding codon 599 of Braf; codons 12 and 13 of $\mathrm{N}-, \mathrm{H}$-, and $\mathrm{K}$-Ras exon 1 ; and codon 61 of $\mathrm{N}-, \mathrm{H}$-, and $\mathrm{K}$-Ras exon 2, respectively, with the PSQ96 SNP Reagent kit (B\&L Systems). Pyrograms were analyzed for deviations from the wild-type sequence.

Along with each lot of PCR reactions, negative controls without DNA and controls without PSQ primer were run, as well as wild-type samples for each gene and exon. Positive controls involved DNA extracted from three papillomas in which $\mathrm{H}$ Ras codon 12 mutations were established earlier by allele-specific oligohybridization (19). The same mutations ( $C>T$ in transcribed strand) showed up in our pyrosequencing assays.

Analyses and statistics. Kaplan-Meier plots were used for initial exploration of treatment and genotype effects. These effects were confirmed using the Cox proportional hazards model in SPSS 10 software package (SPSS, Chicago, IL). Effects of treatments on tumor yield were evaluated at the median survival of the shortest-lived group by ANOVA with post hoc tests by Bonferroni's $t$ test for multiple comparisons.

\section{Results}

Tumors. Depending on treatment, a variety of tumors and skin lesions developed as outlined in Table 1. When appropriate, genotype effects are given below in the text. Only six melanomas were observed, showing a low grade of differentiation and pigmentation with spindle-shaped cells, and a (diffuse) positivity for S100 or Melan-A/Mart-1. One melanoma occurred in an Ink4a/Arf ${ }^{+/+} \mathrm{Xpa}^{-/-}$mouse (experiment 1) and five melanomas in Ink4a/Arf $\mathrm{Al}^{+/,-/-} \mathrm{Xpa}^{+/+}$mice (experiment 2 ), with no obvious bias in genotype or treatment.

Nevi. Melanocytic nevi appeared as accumulations of melanocytes and pigmentloaded macrophages in the dermis. The vast majority of nevi showed no indications of malignancy, either on macroscopic or microscopic histologic inspection ( $7 \%, n=114$ evaluated).

Over the entire first experiment, nevi appeared significantly later in Ink4a/Arf ${ }^{-1}$ $\mathrm{Xpa}^{-/-}$compared with Ink4a/Arf $\mathrm{Ppa}^{+/-}$mice (median latency time, $t_{\mathrm{m}}$, of 131 versus 82 days, respectively, $P=0.004$; Fig. $1 A)$; this difference was most pronounced with neonatal UV exposure followed by 6 MED every fortnight $\left(t_{\mathrm{m}}\right.$ : 140 days versus 74, $P=0.0022$; Fig. $1 B$ ). Moreover, the overall numbers of nevi per animal (yields) were higher in Ink4a/Arf ${ }^{+/-}$compared with Ink4a/Arf ${ }^{-1-}: 2.5$ versus 0.8 nevi per animal at day 140 . Notably, this was the only skin lesion in our study of which the induction was slowed down in the Ink4a/Arf null mice. 


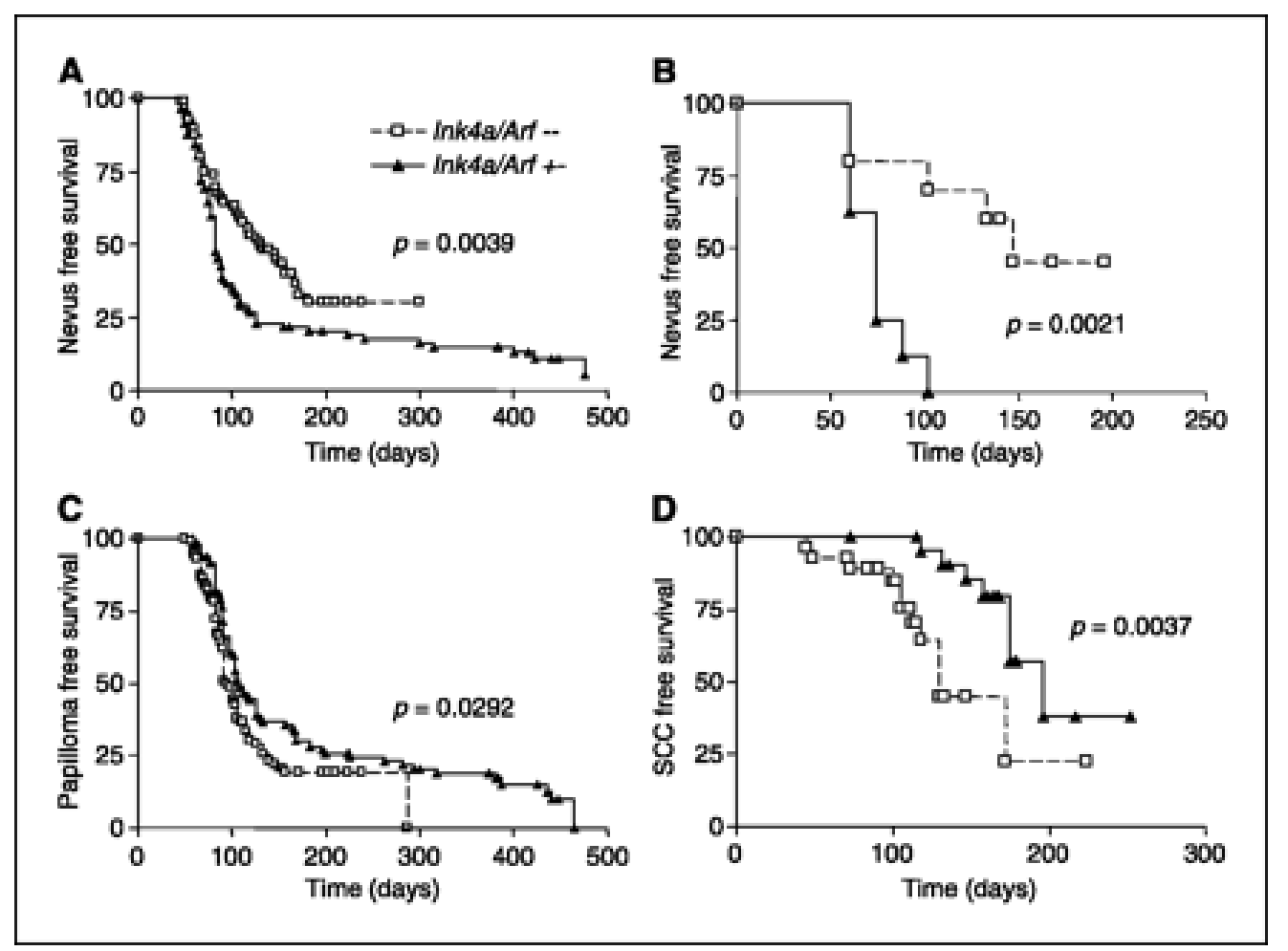

Figure 1. Effect of Ink4a/Arf genotype on carcinogen-induced tumorigenesis. A, nevus-free survival summed for all groups in experiment $1 . B$, nevus-free survival in $\mathrm{Xpa}^{-/-}\left(\right.$Ink4a/Arf ${ }^{+-}$and Ink4a/Arf $\left.{ }^{-1}\right)$ mice neonatally exposed to 4 MED UV on days 3,4 , and 5 , and subsequently to $4 \mathrm{MED} / 2$ weeks. $C$, papilloma-free survival summed for all groups in experiment 1 . $D$, SCC-free survival in mice neonatally exposed to DMBA and after 4 weeks to various UV regimes. The $P$ values represent log-rank test statistics. Note that all tumors except nevi were enhanced by Ink4a/Arf deficiency. 


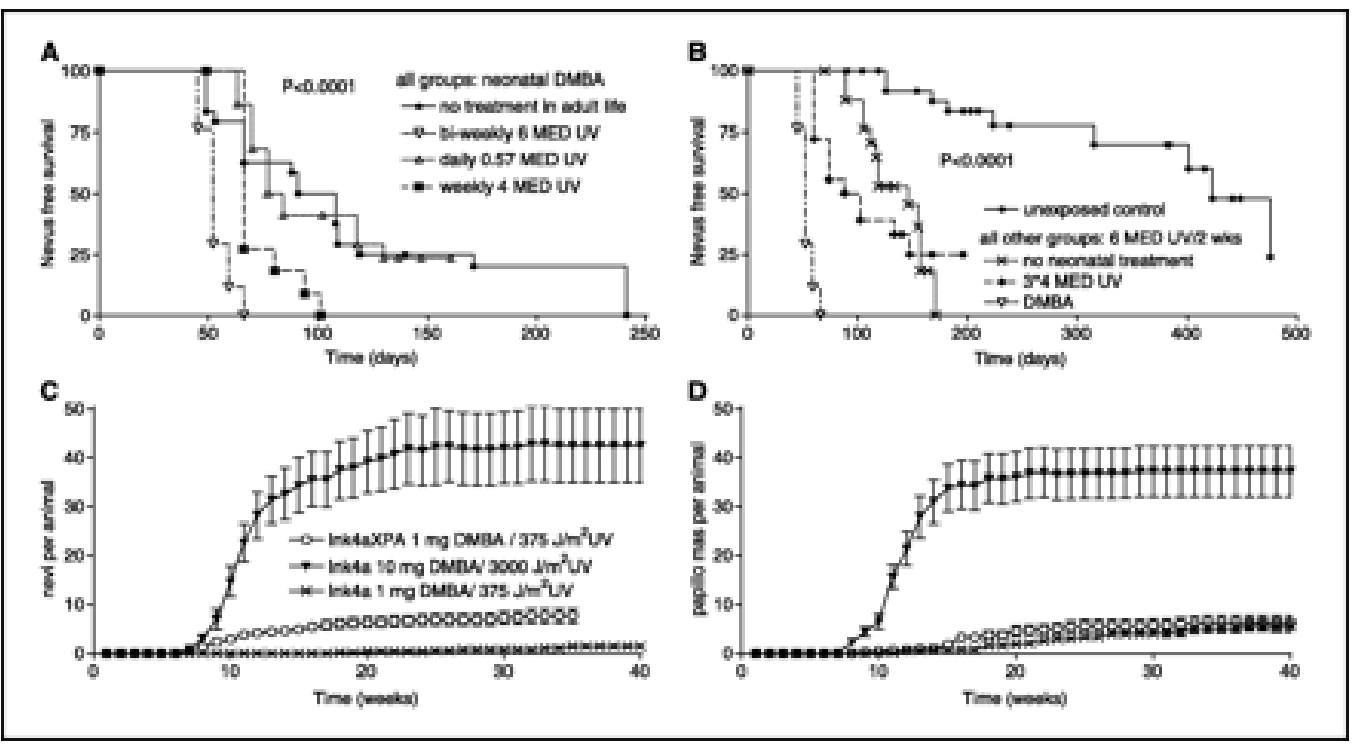

Figure 2. Effect of carcinogen treatments on tumor-free survival. $A$, optimization of the adult treatment regimen for nevi. $B$, comparison of neonatal treatments on nevogenic potential. The $P$ values in $(A$ and $B$ ) represent log-rank test statistics. $C$, comparison of nevus yields between Ink4a/Arf Xpa and Ink4a/Arf mice exposed to the highest tolerated carcinogenic dose for Ink4a/Arf Xpa or Ink4a/Arf mice. $D$, same comparison for papillomas. $C$ and $D$, points, mean; bars, SE.

Neonatal treatment with DMBA, especially in combination with adult erythemal UVB overexposures, remarkably shortened $t_{\mathrm{m}}$ and enhanced yields. Daily suberythemal exposure (4/7 MED) had no discernable effect on nevus development (Fig. 2A). Surprisingly, TPA had no significant effect on nevus-free survival, although it raised nevus yields $>2$-fold compared with controls that received only DMBA.

As 6 MED UVB per fortnight was the most effective stimulus of nevus development, this regimen was used to compare the effects of the neonatal treatments with DMBA, UVB, or no exposure. Although more slowly than DMBA, neonatal UVB also induced nevi as shown in Fig. $2 B$. Correspondingly, nevus yields dropped when DMBA was replaced by UVB.

Experiment 2 used $X p a$ wild-type mice that could be exposed to 10 times higher DMBA concentrations and 8 times higher UVB levels, as their acute sensitivity to these challenges was much lower than that of $\mathrm{Xpa}^{-/-}$mice.

Although the $t_{\mathrm{m}}$ for nevi was almost identical for the groups exposed to DMBA and 6 MED UVB per fortnight, the yields eventually rose 5.5-fold higher in $\mathrm{Xpa}^{+/+}$than in $X \mathrm{pa}^{-/-}$mice when both were exposed to their respective highest tolerated doses. When Xpa wild types were exposed to the same physical doses as the $X p a^{-}$ /- mice, nevi appeared 2.5 times later than in $\mathrm{Xpa}^{-/-}$mice, and eventually reached 5.1-fold lower numbers (Fig. 2C).

Papillomas. Papillomas were morphologically presented as hyperplastic keratinocytes protruding from the epidermal surface and positive for pancytokeratin.

Over the entire first experiment, papillomas were slightly augmented in Ink4a/Arf ${ }^{\prime-}$ compared with Ink4a/Arf ${ }^{+/-}$mice $\left(t_{\mathrm{m}}\right.$ of 95 versus 108 days, respectively, $P=$ 
0.03; Fig. 1C). Correspondingly, the numbers of papillomas per animal were higher in Ink4a/Arf ${ }^{--} \mathrm{Xpa}^{-/-}$mice compared with Ink4a/Arf ${ }^{+-} \mathrm{Xpa}^{-/-}$mice.

All neonatal and adult treatments used in these studies raised papilloma yields and prevalences but the differences between adult treatment regimens were small and statistically insignificant. Generally, earlier onset of papillomas was associated with higher numbers of papillomas per animal (Table 1 ). The papilloma yields for $X p a$ wild-type mice (experiment 2) were remarkably higher than for $\mathrm{Xpa}^{-/-}$mice (experiment 1) when both were exposed at their respective highest tolerated doses. However, when the same physical doses were used, yields were slightly higher in $\mathrm{Xpa}^{-/-}$mice (Fig. 2D).

Squamous cell carcinomas. SCCs were characterized by infiltratively growing keratinocytes, keratinization, and a positive immunohistochemical staining with pan-cytokeratin.

On average, SCCs occurred $* 3$-fold earlier in Ink4a/Arf ${ }^{-1-} \mathrm{Xpa}^{-/-}$mice than in Ink4a/Arf ${ }^{+/-} \mathrm{Xpa}^{-/-}$mice, but this difference was not evident in the separate treatments due to the small numbers of tumors. The overall effect of genotype on UV-induced SCC formation is illustrated in Fig. 1D. SCCs appeared earlier and in higher numbers with 4/7 MED/d than with 4 MED weekly.

Sarcomas. S.c. pleiomorphic spindle cell tumors, morphologically presenting with a low grade of differentiation, often highly infiltrated with lymphocytes, densely vascularized, and negative for the immunohistochemical markers S100, MelanA/Mart-1, Trp-1, Trp-2, and pan-cytokeratin were categorized as (unspecified) sarcomas.

Sarcoma prevalence was affected by Ink4a/Arf genotype and treatments. Although not evident from the small number of tumors in each treatment, averaged over the DMBA-treated groups in experiment 1 , sarcoma yield was 3.5fold higher in the Ink4a/Arf ${ }^{-1}$ mice compared with Ink4a/Arf ${ }^{+-}$mice $(P=0.005)$. Further, combinations of neonatal DMBA or UV exposure and adult intermittent erythemal UV exposure raised sarcoma yields (Table 1).

Cysts. Epidermal cysts in the dermis morphologically presented as spheres of inward differentiating keratinocytes converging on central keratin deposits and often contained melanin pigment.

The occurrence of cysts was not affected by the Ink4a/Arf genotype. Cysts appeared remarkably earlier and with higher yields in $\mathrm{Xpa}^{+/+}$mice exposed neonatally to UVB (Table 1 ).

Other tumors. Generalized lymphoma appeared as large nodules of histologically proven lymphocytes in multiple organs, such as liver and spleen. Ink4a/Arf ${ }^{-1}$

mice were strongly predisposed to develop lymphomas as opposed to Ink4a/Arf ${ }^{+/-}$ mice. None of the treatments had an effect on lymphoma-free survival.

Other tumors were rare and included s.c. hemangiomas, showing widely dilated and aberrantly growing vascular channels and internal tumors at various locations.

Genetic analyses of nevi and melanomas. PCR-amplified DNA extracted from microdissected nevi $(n=46)$ and melanomas $(n=6)$ gave informative sequences in $74 \%$ of the 287 samples tested. The vast majority of these samples contained 
no hotspot mutations in $\mathrm{H}-, \mathrm{N}-$, and $\mathrm{K}$-Ras codons 12,13 , or 61 as found in UV and DMBA-induced tumors, or the Braf codon 599 mutation as found in human nevi. Two nevi, however, contained mutations in $K$-Ras exon 1 and $N$-Ras exon 2 (Table 2).

Proliferation marker responses in nevi and melanomas. Sections from 33 nevi were stained for phospho-ERK1/2, Ki-67, and p53 (melanin was bleached and murine skin carcinomas served as positive controls). All but one were found to be negative for $\mathrm{pERK} 1 / 2$, and all were negative for $\mathrm{p} 53$. The majority of nevi was negative for Ki-67. Only two nevi (6\%) showed scattered Ki-67-positive cells; one contained a small nest of pERK1/2-positive cells that coincided with $\mathrm{Ki}-67$ positivity. The two Ki-67 positive nevi originated from an Ink4a/Arf ${ }^{-1} \mathrm{Xpa}^{+/+}$and an Ink4a/Arf ${ }^{+/-} \mathrm{Xpa}^{-/-}$mouse that both received neonatal sham treatment and biweekly 6 MED exposures. All six melanomas were negative for pERK $1 / 2$ but showed an abundance of Ki-67-positive cells.

\section{Discussion}

This study compared several neonatal and adult treatments for their effects on nevus and melanoma development in mice. Although nevi rarely progressed to melanomas, remarkable differences in nevus size, multiplicity, and nevus-free survival were observed between treatments. Intermittent exposures to erythemal UVB doses ( $4 \mathrm{MED} / \mathrm{wk}$ or $6 \mathrm{MED} /$ fortnight) caused a marked increase in nevus size and number and corresponding decrease in nevus-free survival compared with groups receiving low daily exposure (4/7 MED) or controls receiving no treatment in adulthood. An accelerating effect of intermittent erythemal UVB exposures on nevi was also found when neonatal DMBA exposure was replaced by neonatal UVB exposures.

Together, these data confirm the epidemiologic observation in humans that sunburns increase nevus numbers in contrast to chronic low exposures (25). Furthermore, the contrasting effects of intermittent erythemal and daily suberythemal UVB exposures match well with earlier experiments: single erythemal exposures stimulated murine melanocyte proliferation, whereas fractionated exposures were ineffective (26). Similarly, exposure of human nevi to erythemagenic doses of UVB radiation led to an increase in proliferation markers within 4 days after exposure as opposed to repeated suberythemagenic exposures (27). Taken together, these results show that erythemagenic UVB exposures are powerful stimuli of melanocyte proliferation and nevi formation, in contrast to equal total doses fractionated into suberythemal exposures. Given the release of melanocyte-stimulating cytokines and growth factors such as endothelin-1 and stem cell factor by keratinocytes in erythemous skin (28-30), it is conceivable that paracrine stimulation contributes to melanocyte proliferation induction and nevus development.

The chemical promoter TPA had only minor effects on nevus formation in our study and did not enhance melanoma formation in Tyr-Ras mice treated with DMBA (31). These results suggest that in doses that are effective on keratinocytic tumors, TPA is only a weak promotor of melanocyte hyperproliferation, in contrast to intermittent UVB overexposure.

Neonatal treatment with DMBA or UVB radiation enhanced, but was no prerequisite for, the formation of nevi (i.e., nevi also arose in untreated control mice and in mice UV exposed only in adulthood). The enhancement of nevus formation by neonatal UVB exposures resembles the epidemiologic finding that neonatal UVB exposures contribute to nevus development (32). The greater 
efficacy of DMBA than UV in neonatal exposure may result from several factors. First, DMBA dissolved in acetone may penetrate through hair shafts deeper into the skin than UV radiation and consequently affect directly the many melanocytes residing at the root of the hair shaft. Second, the mutagenic potential of DMBA DNA adducts may be greater than that of UV-induced DNA adducts. Third, melanin may provide better protection against UV radiation than against DMBA.

Besides the treatment effects, deficiencies in either Xpa or Ink4a/Arf showed prominent effects on nevus formation. When mice were exposed to identical low doses, nevus numbers were 5 -fold higher in $\mathrm{Xpa}^{-/-}$than in $\mathrm{Xpa}^{+/+}$mice, indicating a role of nucleotide excision repair in preventing nevus formation. However, the high acute sensitivity to UV radiation and DMBA prohibited higher exposures of $\mathrm{Xpa}^{-/-}$mice. When $\mathrm{Xpa}^{+/+}$mice were exposed to their highest tolerated dose, nevus numbers rose 27 -fold higher than when these mice were exposed to an 8fold lower dose, equal to the highest tolerated dose for $X \mathrm{pa}^{-/-}$mice. Thus, the maximum attainable yield of nevi in $\mathrm{Xpa}^{+/+}$mice far exceeded that attainable in $X \mathrm{pa}^{-/-}$mice (Fig. $3 A$ versus $B$ ).

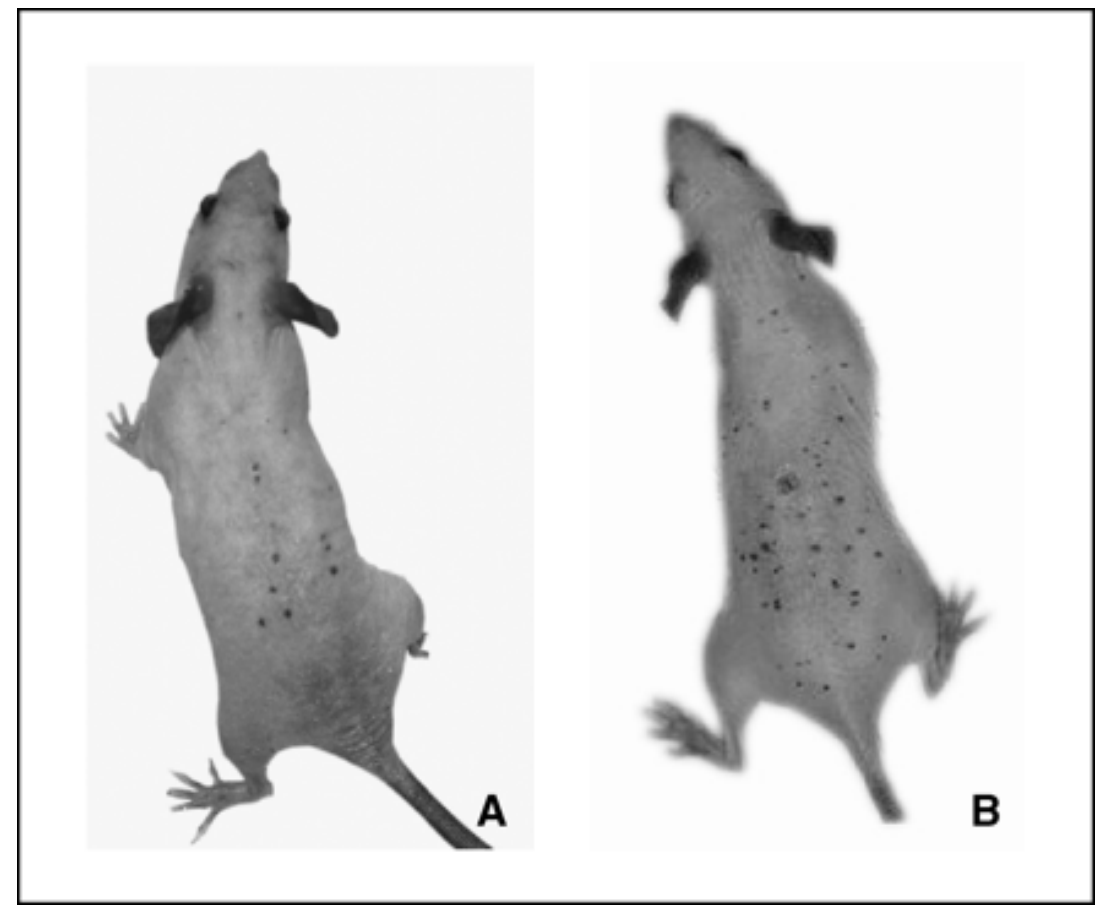

Figure 3. Comparison of Xpa knockout and wild-type mouse exposed to their respective highest tolerated doses. $A$, Ink $4 a^{-/-} \mathrm{Xpa}^{-/-}$mouse neonatally exposed to $0.01 \mathrm{mg}$ DMBA and as an adult to $375 \mathrm{~J} / \mathrm{m}^{2} \mathrm{UV} / 2$ weeks. $B$, Ink $4 a^{-/-}$mouse exposed neonatally to $0.1 \mathrm{mg}$ DMBA and to $3 \mathrm{~kJ} / \mathrm{m}^{2} \mathrm{UV} / 2$ weeks, photographed at 15 weeks of age.

Remarkably, the combined $\mathrm{p} 16^{\text {Ink4a }} \mathrm{p} 19^{\text {Arf }}$ deficiency inhibited nevus development, whereas most other skin tumors were stimulated by this deficiency. This may indicate that the critical cell cycle checkpoints upon UV irradiation are regulated differently in melanocytes than in keratinocytes. Our group found no apparent in vivo effects of Ink4a/Arf ${ }^{-1}$ genotype on UV-induced cell cycle arrest and apoptosis in keratinocytes, ${ }^{6}$ but a lack of p16 has been reported to abrogate UV-induced $\mathrm{G}_{2}$ arrest in melanoma cell lines (33). Such a failure in $\mathrm{G}_{2}$ arrest may conceivably 
compromise the survival of normal melanocytes with DNA damage and thus impair nevus development.

The regimens that most effectively induced nevi in our experiments (i.e., neonatal and intermittent UV exposure) were also related to increased melanoma risk in humans, but melanomas were rare in our experiments. In earlier experiments (16), DMBA treatment and subsequent exposure to UVB radiation produced melanomas in $25 \%$ of hairless mice; a substantially higher percentage than in our experiments. This discrepancy may possibly be attributed to differences in mouse strains and exposure regimens.

The experiments with $\mathrm{Xpa}^{+/+}$mice yielded more melanomas (in $8 \%$ of 64 carcinogenically challenged mice) than experiments with $X \mathrm{pa}^{-/-}$mice (in $0.5 \%$ of 205 carcinogenically challenged mice). The lower carcinogenic dosages that had to be used on the $\mathrm{Xpa}^{-/-}$mice apparently very much restricted the melanoma yield attainable in these mice. No obvious preference for melanoma development in either Ink4a/Arf ${ }^{/-}$or Ink4a/Arf ${ }^{+/-}$mice was noted, but the low number of melanomas hampers any firm conclusion beyond the fact that the present experiments were ineffective in raising melanoma. As opposed to the current UVinducible melanoma models that are based on prior receptor tyrosine kinase pathway activation (34), we attempted to establish a UV-inducible melanoma model based on prior inactivation of the $\mathrm{p} 16^{\text {Ink4a }}$ and/or $\mathrm{p} 14^{\text {Arf }}$ pathways. Although p16 $6^{\text {Ink4a }}$-specific knock-in models form melanomas upon DMBA exposure $(7,35)$, their responses to UV exposure remain to be established.

Given the large increase of melanoma incidence in $H-R a s^{G 12 V}$ mice when crossbred with Ink4a/Arf knockouts (18), it is questionable whether the present experiments with Ink4a/Arf knockout mice were effective in introducing oncogenic changes strong or specific enough to express the higher melanoma risk in these mice. To investigate this point more closely, we analyzed the experimentally induced nevi for hotspot mutations in Ras or Braf genes, activation of pERK1/2 (downstream of Ras), proliferative activity (i.e., cycling cells expressing Ki67), and p53 expression (halting cell cycle progression, e.g., in senescence).

We collected nevus biopsies from mice of various genotypes and different exposure regimens and microdissected pigmented sections to restrict samples to melanocytes. Pyrosequencing of the extracted and PCR-amplified DNA rarely detected activating Braf, $\mathrm{N-}, \mathrm{H}$-, and $\mathrm{K}$-Ras hotspot mutations commonly found in human melanomas and nevi.

The absence of a strong expression of phosphorylated ERK $1 / 2$ indicated that this branch of the Ras pathway was not activated in the nevi. Moreover, Ki67 positive cells were generally rare in the nevi, indicating a very low proliferation. p53 expression was not found in nevi, indicating it played no role in stagnation of nevus growth.

Apparently, these nevi arose from a transient burst (or repeated bursts) of proliferation in some melanocytes which subsequently halted as a certain contiguous mass of melanocytes was formed. In contrast to the singular interfollicular melanocytes, the melanocytes in these nevi were deeply pigmented (impermeable to UV light), possibly indicating an advanced stage of differentiation. In contrast, $\mathrm{Ki}-67$ stained positive in all melanomas, supporting the notion that these tumors were indeed malignant and highly proliferative.

Differences in the induction of nonmelanocytic tumors were most strongly determined by the differences in genotypes. The homozygous Xpa knockout led to 
an increased sensitivity for UV-induced SCCs and papillomas, as described earlier (19). Ink4a/Arf ${ }^{-1-}$ mice had an increased susceptibility to spontaneous lymphoma formation and to UVB/DMBA-induced sarcomas, papillomas and SCCs. These results are consistent with earlier reports (6). The enhanced formation of papillomas and SCCs in the absence of a functional $p 16^{\text {Ink4a }}$ gene supports the functional role of $p 16^{\operatorname{Ink} 4 a}$ mutations in human SCCs (20).

Treatment effects on nonmelanocytic tumors included the neonatal UVB-provoked augmentation of epidermal cysts, which differ morphologically to spontaneous cysts in hairless mice (36). This effect was only significant in experiment 2 with Xpa wild-type mice with higher dosages. Carcinomas tended to be more effectively induced by chronic than intermittent UV exposure, but this effect was not firm due to censoring deaths under the latter regimen and consequently low numbers of carcinomas. This is in agreement with earlier observations that fractionation of exposure enhances SCC development (37). Remarkably, the incidence of papillomas was unaffected by dosage fractionation demonstrating that total accumulated exposure determines papilloma risk, regardless of the occurrence of sunburns.

In conclusion, intermittent erythemal UVB exposures were more effective in promoting nevus development than equal weekly dosages spread over daily suberythemal exposures, in contrast to the dose fraction effects on nonmelanocytic tumor types. Furthermore, the prevalence and growth of nevi were impaired in homozygous Ink4a/Arf knockouts compared with heterozygotes. Surprisingly, the multiple nevi induced in homozygous Ink4a/Arf knockout mice showed very little tendency to progress to malignant melanoma, which may be related to the lack of hotspot mutations in Braf and $\mathrm{N}$-Ras genes. 


\section{Acknowledgments}

Grant support: National Dutch Cancer Foundation grant RUL2000-2303 and European Commission grant QLK4-1999-01084.

The costs of publication of this article were defrayed in part by the payment of page charges. This article must therefore be hereby marked advertisement in accordance with 18 U.S.C. Section 1734 solely to indicate this fact.

We thank Heggert Rebel (Dermatology, Leiden University Medical Centre) and Anja Westerman-de Vries (National Institute of Public Health and the Environment) for technical assistance; Enno Dreef (Pathology, Leiden University Medical Centre) and John Zevenhoven (Nederlands Kanker Instituut, Amsterdam, the Netherlands) for immunohistochemical protocols; Ron Wolterbeek (Medical Statistics Department, Leiden University Medical Centre) for advise on statistical analyses; Marjon Pasmooij (Academisch Ziekenhuis Groningen, Groningen, the Netherlands) and Kees Tensen (Dermatology, Leiden University Medical Centre) for advice on analytic assays; Martin van der Valk (Nederlands Kanker Instituut), Wolter Mooi (Vrije Universiteit Medisch Centrum, Amsterdam, the Netherlands), and Johan Toonstra (University Medical Centre Utrecht) for aid in the crucial pathologic evaluations; Dr. H. van Steeg (National Institute of Public Health and the Environment) for the kind gift of Xpa knockout mice; and Drs. R. DePinho and L. Chin (Dana-Farber Cancer Institute, Boston, MA) for providing $p 16^{\text {Ink4a }} / p 19^{\text {Arf }}$ knockout mice.

\section{Footnotes}

Note: A. van Schanke is currently at NV Organon, Toxicology and Drug Disposition Department, Schaijk, the Netherlands.

${ }^{6}$ M. Sutmuller, personal communication. 


\section{References}

1. Elwood JM, Jopson J. Melanoma and sun exposure: an overview of published studies. Int J Cancer 1997; 73:198-203.

2. Hayward NK. Genetics of melanoma predisposition. Oncogene 2003;22:3053-62.

3. Sharpless NE, De Pinho RA. The INK4A/ARF locus and its two gene products. Curr Opin Genet Dev 1999;9:22-30.

4. Pomerantz J, Schreiber-Agus N, Liegeois NJ, et al. The Ink4a tumor suppressor gene product, p19 ${ }^{\text {Arf }}$, interacts with MDM2 and neutralizes MDM2's inhibition of p53. Cell 1998;92:713-23.

5. Eskandarpour M, Hashemi J, Kanter L, et al. Frequency of UV-inducible NRAS mutations in melanomas of patients with germline CDKN2A mutations. JNCI Cancer Spectrum 2003;95:790.

6. Serrano M, Lee $H$, Chin $L$, et al. Role of the INK4a locus in tumor suppression and cell mortality. Cell 1996;85:27-37.

7. Sharpless NE, Kannan K, Xu J, Bosenberg MW, Chin L. Both products of the mouse Ink4a/Arf locus suppress melanoma formation in vivo. Oncogene 2003;22:5055-9.

8. Daniotti M, Oggionni M, Ranzani T, et al. BRAF alterations are associated with complex mutational profiles in malignant melanoma. Oncogene 2004;23:5968-77.

9. Keller-Melchior R, Schmidt R, Piepkorn M. Expression of the tumor suppressor gene product p16INK4 in benign and malignant melanocytic lesions. J Invest Dermatol 1998;110:932-8.

10. Bennett DC. Human melanocyte senescence and melanoma susceptibility genes. Oncogene 2003;22:3063-9.

11. Brash DE, Rudolph JA, Simon JA, et al. A role for sunlight in skin cancer: UV-induced p53 mutations in squamous cell carcinoma. Proc Natl Acad Sci U S A 1991;88:10124-8.

12. Daya-Grosjean L, Sarasin A. UV-specific mutations of the human patched gene in basal cell carcinomas from normal individuals and xeroderma pigmentosum patients. Mutat Res 2000;450:193-9.

13. Kraemer $\mathrm{KH}$, Lee MM, Andrews AD, Lambert WC. The role of sunlight and DNA repair in melanoma and nonmelanoma skin cancer. The xeroderma pigmentosum paradigm. Arch Dermatol 1994;130:1018-21.

14. Epstein JH, Epstein WL, Nakai T. Production of melanomas from DMBA-induced "blue nevi" in hairless mice with ultraviolet light. J Natl Cancer Inst 1967;38:19-30.

15. Romerdahl CA, Stephens LC, Bucana C, Kripke ML. The role of ultraviolet radiation in the induction of melanocytic skin tumors in inbred mice. Cancer Commun 1989;1:209-16.

16. Husain Z, Pathak MA, Flotte T, Wick MM. Role of ultraviolet radiation in the induction of melanocytic tumors in hairless mice following 7,12-dimethylbenz(a)anthracene application and ultraviolet irradiation. Cancer Res 1991;51:4964-70.

17. de Gruijl FR, van Kranen $\mathrm{HJ}$, van Schanke A. UV exposure, genetic targets in melanocytic tumors and transgenic mouse models. Photochem Photobiol 2005;81:52-64.

18. Chin L, Pomerantz J, Polsky D, et al. Cooperative effects of INK4a and ras in melanoma susceptibility in vivo. Genes Dev 1997;11:2822-34.

19. de Vries A, Berg RJ, Wijnhoven S, et al. XPA-deficiency in hairless mice causes a shift in skin tumor types and mutational target genes after exposure to low doses of U.V.B. Oncogene $1998 ; 16: 2205-12$. 
20. Soufir N, Moles JP, Vilmer C, et al. P16 UV mutations in human skin epithelial tumors. Oncogene 1999;18:5477-81.

21. de Vries A, van Oostrom CT, Hofhuis FM, et al. Increased susceptibility to ultraviolet-B and carcinogens of mice lacking the DNA excision repair gene XPA. Nature 1995;377:169-73.

22. Rebel H, Mosnier LO, Berg RJ, et al. Early p53-positive foci as indicators of tumor risk in ultraviolet-exposed hairless mice: kinetics of induction, effects of DNA repair deficiency, and p53 heterozygosity. Cancer Res 2001;61:977-83.

23. Berg RJ, de Vries A, van Steeg $H$, de Gruijl FR. Relative susceptibilities of XPA knockout mice and their heterozygous and wild-type littermates to UVB-induced skin cancer. Cancer Res 1997;57:581-4.

24. Rebel H, van Steeg H, Beems RB, et al. Suppression of UV carcinogenesis by difluoromethylornithine in nucleotide excision repair-deficient Xpa knockout mice. Cancer Res $2002 ; 62: 1338-42$.

25. Holman CD, Armstrong BK. Cutaneous malignant melanoma and indicators of total accumulated exposure to the sun: an analysis separating histogenetic types. J Natl Cancer Inst $1984 ; 73: 75-82$.

26. van Schanke A, Jongsma MJ, Bisschop R, et al. Single UVB overexposure stimulates melanocyte proliferation in murine skin, in contrast to fractionated or UVA-1 exposure. J Invest Dermatol 2005;124:241-7.

27. Tronnier $M$, Rudolph $P$, Koser $T$, Raasch $B$, Brinckmann J. One single erythemagenic UV irradiation is more effective in increasing the proliferative activity of melanocytes in melanocytic naevi compared with fractionally applied high doses. $\mathrm{Br}$ J Dermatol 1997;137:534-9.

28. Ahn GY, Butt KI, Jindo $\mathrm{T}$, et al. The expression of endothelin-1 and its binding sites in mouse skin increased after ultraviolet B irradiation or local injection of tumor necrosis factor $\boldsymbol{\alpha}$. J Dermatol 1998;25:78-84.

29. Kligman LH, Murphy GF. Ultraviolet B radiation increases hairless mouse mast cells in a dosedependent manner and alters distribution of UV-induced mast cell growth factor. Photochem Photobiol 1996;63:123-7.

30. Hachiya A, Kobayashi A, Ohuchi A, Takema Y, Imokawa G. The paracrine role of stem cell factor/c-kit signaling in the activation of human melanocytes in ultraviolet-B-induced pigmentation. J Invest Dermatol 2001;116:578-86.

31. Powell MB, Gause PR, Hyman P, et al. Induction of melanoma in TPras transgenic mice. Carcinogenesis 1999;20:1747-53.

32. Dulon $M$, Weichenthal $M$, Blettner $M$, et al. Sun exposure and number of nevi in 5- to 6-yearold European children. J Clin Epidemiol 2002;55:1075-81.

33. Milligan A, Gabrielli BG, Clark JM, et al. Involvement of $\mathrm{p} 16^{\text {INK4a }}$ in cell cycle delays after low dose UV radiation. Mutat Res 1998;422:43-53.

34. Noonan FP, Recio JA, Takayama H, et al. Neonatal sunburn and melanoma in mice. Nature $2001 ; 413: 271-2$.

35. Krimpenfort P, Quon KC, Mooi WJ, Loonstra A, Berns A. Loss of p16 Ink4a confers susceptibility to metastatic melanoma in mice. Nature 2001;413:83-6.

36. Mann SJ. Hair loss and cyst formation in hairless and rhino mutant mice. Anat Rec 1971;170:485-99.

37. Forbes PD, Davies RE. Photocarcinogenesis in hairless mice: dose response and influence of dose-delivery. In: Daynes RA, Spikes JD, editors. Experimental and Clinical Photoimmunology. Vol. 1. Boca Raton (Florida): CRC Press; 1983. p. 43-60. 